\title{
H-index and How to Improve it?
}

\section{Izet Masic}

\begin{abstract}
The h-index is an index that attempts to measure both the productivity and citation impact of the published work of a scientist or scholar. The index is based on the set of the scientist's most cited papers and the number of citations that they have received in other publications and on the distribution of citations received by a given researcher's publications. The $\mathrm{h}$-index is important for individual users as well as scientific research institutions, universities and main journal editors. There are a lot of methods to improve your h-score. It takes a lot of work and to promote papers and journals, but it is all part of developing as a researcher, working together with your community and improving communication methods.
\end{abstract}

Keywords: H-index, Impact, Research.

How to cite this article: Masic I. H-index and How to Improve it? Donald School J Ultrasound Obstet Gynecol 2016;10(1):83-89.

\section{Source of support: Nil}

Conflict of interest: None

\section{INTRODUCTION}

Evaluation of the quality and relevance of articles, after they have been accepted and published as scientific papers, which should be the result of serious research work, relies mainly on the qualified members of the academic community, who are of the same or similar professional interests. ${ }^{1-6}$ Being a part of the academic community, we often encounter terms, such as indexing, and citations. According to the Tibor Toth, who wrote in an article published on the website of open encyclopedia of information: Indexing is a term that derives from the concept of index of publications, such as Index Medicus, Science Citation Index and Current Contents. ${ }^{2,3}$

The assessment of the achievement of every scientist, and thus indirectly determining his reputation in the scientific community of these publications, especially journals, is done through the so-called impact factor.? Impact factor shows how many times a scientific article in a specific journal receives average number of quotes (citations) (Graphs 1 and 2). The idea of impact factor for

\section{Professor}

Faculty of Medicine, University of Sarajevo, Bosnia and Herzegovina

Corresponding Author: Izet Masic, Professor, Faculty of Medicine, University of Sarajevo, Bosnia and Herzegovina e-mail: imasic@lol.ba the first time is mentioned by the American researcher Eugene Garfield, in an article published in the journal of 'Science' in 1955, which was the basis for the publication of the science citation index (SCI) in 1961. Today, the journal impact factor is extracted from publication under the title journal citation reports (JCR), which is produced by Thomson Reuter's publishers. The best measure of the importance of the journal is its echo factor, which shows how many articles published in it are cited. ${ }^{7,8}$ For example, if the journal has impact factor from 0.10 to 0.30 in a certain period, it means that on average every tenth to every third article published in the journal is cited once. In other words, the impact factor tells us how much the journal is used, or how much it is important for the scientists.

Evaluation of scientific productivity and assessment of the published articles of researchers and scientists can be made through the so-called h-index..$^{2-4,6,8}$ Index is calculated on the basis of the list of publications ranked in the order of time when they are quoted. The value of this index is equal to the number of documents $(\mathrm{N})$, in the list that have $\mathrm{N}$ or more citations.

The quality of published results of a scientific work largely depends on the knowledge resources that have been used in the preparation of it, which means that it should be considered to serve the purpose and the very relevance of the information used for it. The relevance of data for research specifically described and contributes the search for resources.

In the ranking of the journal in terms of their qualitative contributions to science research valuable contribution brings SCImago Journal and Country Rank, as Internet portals that publish indicators of journals from countries around the world. This instrument for measuring the scientific competitiveness on a global scale was developed based on the source of information contained in the Scopus database.

\section{H-INDEX}

The h-index is an index that attempts to measure both the productivity and citation impact of the published work of a scientist or scholar. The index is based on the set of the scientist's most cited papers and the number of citations that they have received in other publications. The index can also be applied to the productivity and impact of a as well as a group of scientists, such as a department or university or country. ${ }^{4}$ 


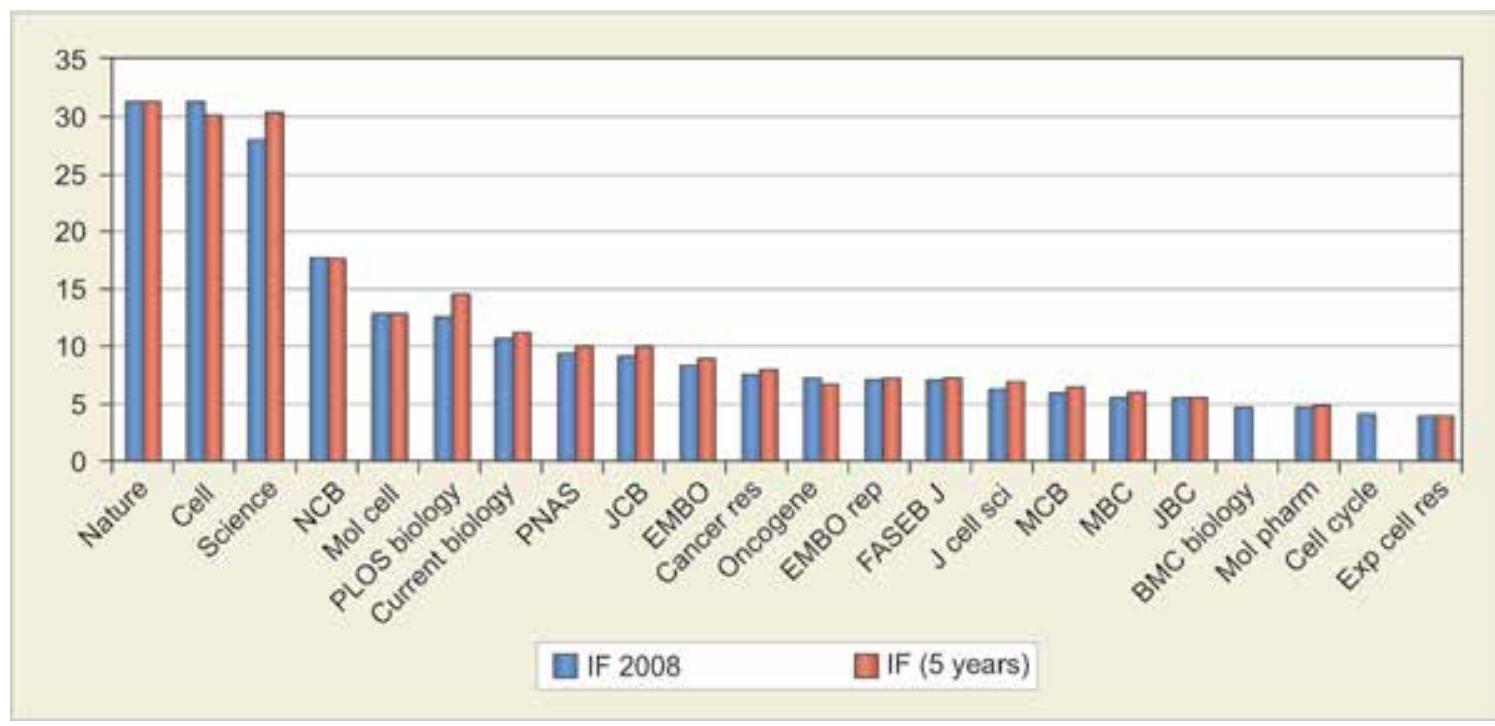

Graph 1: Impact factor journal ranking ${ }^{9}$

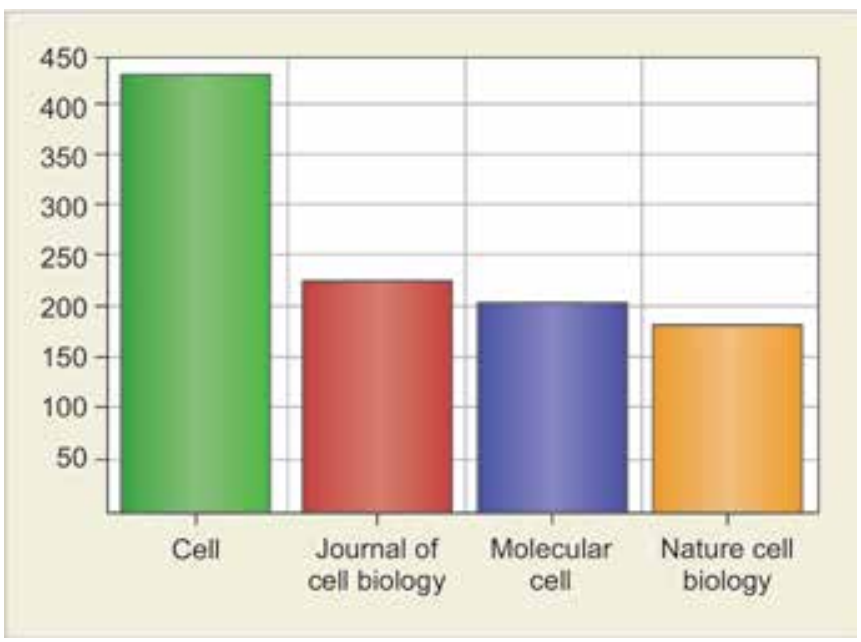

Graph 2: $\mathrm{H}$-index of the four most cited journals ${ }^{10,11}$

The index was suggested in 2005 by Jorge E Hirsch, as a tool for determining theoretical physicists' relative quality and is sometimes called the Hirsch index or Hirsch number. ${ }^{4}$

The index is based on the distribution of citations received by a given researcher's publications. Hirsch writes: A scientist has index $\mathrm{h}$ if $\mathrm{h}$ of his/her number of papers $(\mathrm{Np})$ have at least $\mathrm{h}$ citations each, and the other $(\mathrm{Np}-\mathrm{h})$ papers have no more than $\mathrm{h}$ citations each.

In other words, a scholar with an index of $h$ has published $\mathrm{h}$ papers each of which has been cited in other papers at least $\mathrm{h}$ times. Thus, the h-index reflects both the number of publications and the number of citations per publication. The index is designed to improve upon simpler measures, such as the total number of citations or publications. The index works properly only for comparing scientists working in the same field; citation conventions differ widely among different fields. ${ }^{4}$

The h-index is important for individual users as well as scientific research institutions, universities and main journal editors. As we saw, there is a way to calculate the values of $\mathrm{h}$-index for individual authors, for every article, institution, publishing house or journal. Any of these users try to maximize the value of their h-index because it represents a direct evaluation of the quality of their work.

The h-index is and attempt to measure productivity and the impact of the published scientific work of a scientist or student. As such it is applicable to a group of scientists, a country or scientific institution. When calculation the h-index for one author, or a single journal, it reflects the number of published works as well as the number of quotes taken from individual publications.

Despite the fact that its relatively new (it was described for the first time in 2005), the h-index has become an important measure (Figs 1 and 2) of career development. ${ }^{4}$

\section{Weaknesses of the $h$-index ${ }^{13}$}

Critics of the metric suggest it is limited in the following ways:

- It counts a highly-cited paper regardless of why it is being referenced, e.g. for negative reasons

- It does not account for variations in average number of publications and citations in various fields (some traditionally publish and cite less than others)

- It ignores the number and position of authors on a paper

- It limits authors by the total number of publications, so shorter careers are at a disadvantage

- It has relatively low resolution in that many scientists end up in the same range since it gets increasingly difficult to increase the h-index the higher it gets (an h-index of 100 corresponds to a minimum of 10,000 citations). 
H-index and How to Improve it?

\begin{tabular}{|c|c|c|c|c|c|c|c|c|}
\hline & & Country & Documents & $\begin{array}{l}\text { Citable } \\
\text { documents }\end{array}$ & Citations & Self-Citations & $\begin{array}{c}\text { Citations per } \\
\text { Document }\end{array}$ & \\
\hline 1 & ER & United Kingdom & 375.099 & 302.540 & 5.341 .629 & 1.284 .907 & 15,13 & 436 \\
\hline 2 & 国 & Germany & 303.493 & 266.911 & 3.594 .608 & 906.989 & 12,31 & 364 \\
\hline 3 & [1] & France & 208.165 & 179.015 & 2.438 .178 & 486.629 & 12,01 & 356 \\
\hline 4 & 4. & Italy & 187.390 & 166.756 & 2.246 .743 & 446.968 & 12,77 & 333 \\
\hline 5 & $\equiv$ & Netherlands & 111.103 & 99.432 & 1.925 .982 & 332.131 & 19,01 & 325 \\
\hline 6 & $:=$ & Sweden & 70.457 & 65.177 & 1.267 .870 & 200.233 & 18,80 & 278 \\
\hline 7 & $\mathbf{B a}$ & Switzertand & 68.922 & 60.933 & 1.060 .037 & 126.494 & 16,55 & 273 \\
\hline 8 & [1] & Belgium & 55.136 & 49.208 & 843.656 & 104.613 & 16,28 & 253 \\
\hline 9 & $=$ & Spain & 127.422 & 108.542 & 1.075 .971 & 230.548 & 9,23 & 244 \\
\hline 10 & $\mathrm{~m}=$ & Denmark & 37.660 & 33.959 & 667.990 & 91.637 & 18,79 & 229 \\
\hline 11 & + & Fintand & 31.884 & 30.129 & 653.376 & 87.839 & 21,22 & 226 \\
\hline 12 & $\equiv$ & Austria & 42.247 & 37.369 & 530.896 & 66.569 & 13,20 & 184 \\
\hline 13 & 5 & Norway & 26.784 & 24.304 & 406.564 & 53.707 & 16,48 & 181 \\
\hline 14 & [1] & tretand & 15.850 & 13.559 & 196.450 & 15.834 & 14,71 & 140 \\
\hline 15 & 메프 & Greece & 33.217 & 29.673 & 271.456 & 41.735 & 9,72 & 136 \\
\hline 16 & 묘 & Portugal & 10.817 & 9.849 & 99.112 & 11.662 & 10,57 & 110 \\
\hline
\end{tabular}

Fig. 1: H-index according to the authors from particular countries ${ }^{12}$

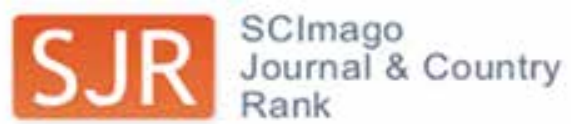

Home
Journal Rankings
Journal Search
Country Rankings
Country Search
Compare
Map Generator
Help
About Us

Science Analysis

The SCImago Journal \& Country Rank is a portal that inctudes the journals and country scientific indicators developed from the information contained in the Scopust database (Etsevier B.V.). These indicators can be used to assess and analyze scientific domains.

This platform takes its name from the SCImago Journal Rank (SJR) indicator 2 , developed by SCImago from the widely known algorithm Google PageRank" This indicator shows the visibility of the journats contained in the Scopuso database from 1996.

Read more about us >

Fig. 2: Available at: https://wiki.oulu.fi/display/tor/1.3.1.7.10+SCImago+Journal+and+Country+Rank (May 02, 2014)

It, like all metrics, is based on data from the past and may not be a valid predictor of future performance. However, in a follow-up publication Jorge Hirsch demonstrated that the h-index is better than other indicators (total papers, total citations, citations per paper) at predicting future scientific achievement. ${ }^{13}$ Some authors consider that the time dependence of the h-index is better than h-index alone, because it is important to describe the expected career evolution of a scientist's work or of a journal's production in a fixed year. ${ }^{14}$

\section{How to Calculate $\mathrm{h}$-index?}

The publication record of an individual and the citation record clearly are data that contain useful information. That information includes the number of papers $(\mathrm{Np})$ published over number of (n) years, the number of citations (Nc) for each paper (j), the journals where the papers were published, their impact parameter, etc. (Figs 3 and 4). This large amount of information will be evaluated with different criteria by different people. ${ }^{4}$

Google Scholar Citations provide a simple way for authors to keep track of citations to their articles. You can check who is citing your publications, graph citations over time, and compute several citation metrics. ${ }^{16}$ The h-index can be calculated using Google Scholar.

In the Web of Science h-factor only scientific articles published in journals which have ISI-recognition (determined by Thomson-Reuters) are considered citeable (so not articles in other journals, chapters in books, etc.). In the Scopus h-factor a larger pool of journals is included, 


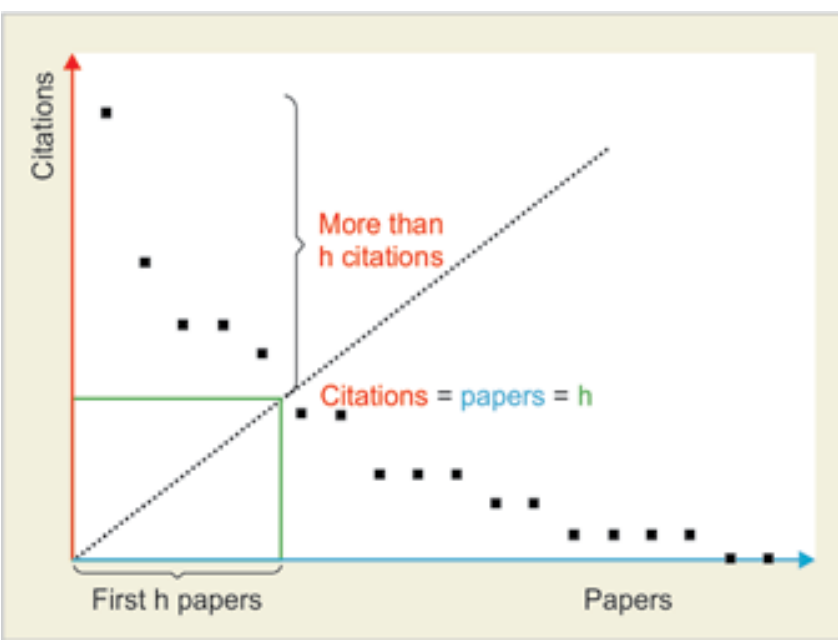

Fig. 3: H-index from a plot of decreasing citations for numbered papers

while in google citations and in 'publish or perish' (www. harzing.com/pop.htm) the h-factor is likely to be higher as it also considers articles in a wide range of journals, book chapters and reports as citable. ${ }^{17}$

\section{How to Improve $\mathbf{h}$-index}

Universities are very competitive environment. Quantitative indicators, like the $\mathrm{h}$-index, are becoming more and more important in this competition. ${ }^{18}$ Despite the fact that its relatively new (it was described for the first time in 2005), the h-index has become an important measure of career development. ${ }^{4}$ A good way to increase citation index is self-citation. More self-citation can double the h-index very fast. A research paper found that many self-citations can even increase the number of citations by others. The citation should be relevant but irrelevant citation can also increase h-index. ${ }^{18}$ Double publication of the some paper for a conference, and later with slightly different name in a paper, can also increase citation index. Both papers should have many self-citations. ${ }^{18}$ Plagiarism is an illegal and unethical way to improve h-index. ${ }^{18}$

Another important way is cooperation with colleges. If you cite your college and he also cites you then you have both significant increases of number of citations. This cooperation can be expanded to a larger unit of people, promoting larger scientific communities and increasing the value and number of citations considerably. ${ }^{18}$

Another way to increase your h-index is self-citation of the paper that has a slightly smaller number of citations than what is your actual h-index. For example, if you have a paper with six citations, and your actual citation number is seven, this single citation will increase your h-score to seven. This is because the paper will now have seven citations. Even irrelevant citation can improve your h-score. On the other hand, if you cite a paper that has a hundred citations, your h-index will not go up. In conclusion, it is preferable to have more papers that were cited a similar number of times, as 10 papers, everyone used as a reference 10 times will give you an h-index score of 10 .

Frequently choosing low quality journals (the best measure of the importance of the journal is its echo actor $)^{19,20}$ and conferences to disseminate paper while some publishers do not prevent you from citing a huge number of irrelevant (also own) works and from writing nonsense. ${ }^{18}$ Collaboration with a famous first author can gain more citation. ${ }^{18}$ Everytime your co-author gets cited, or self-cites, you also get cited.

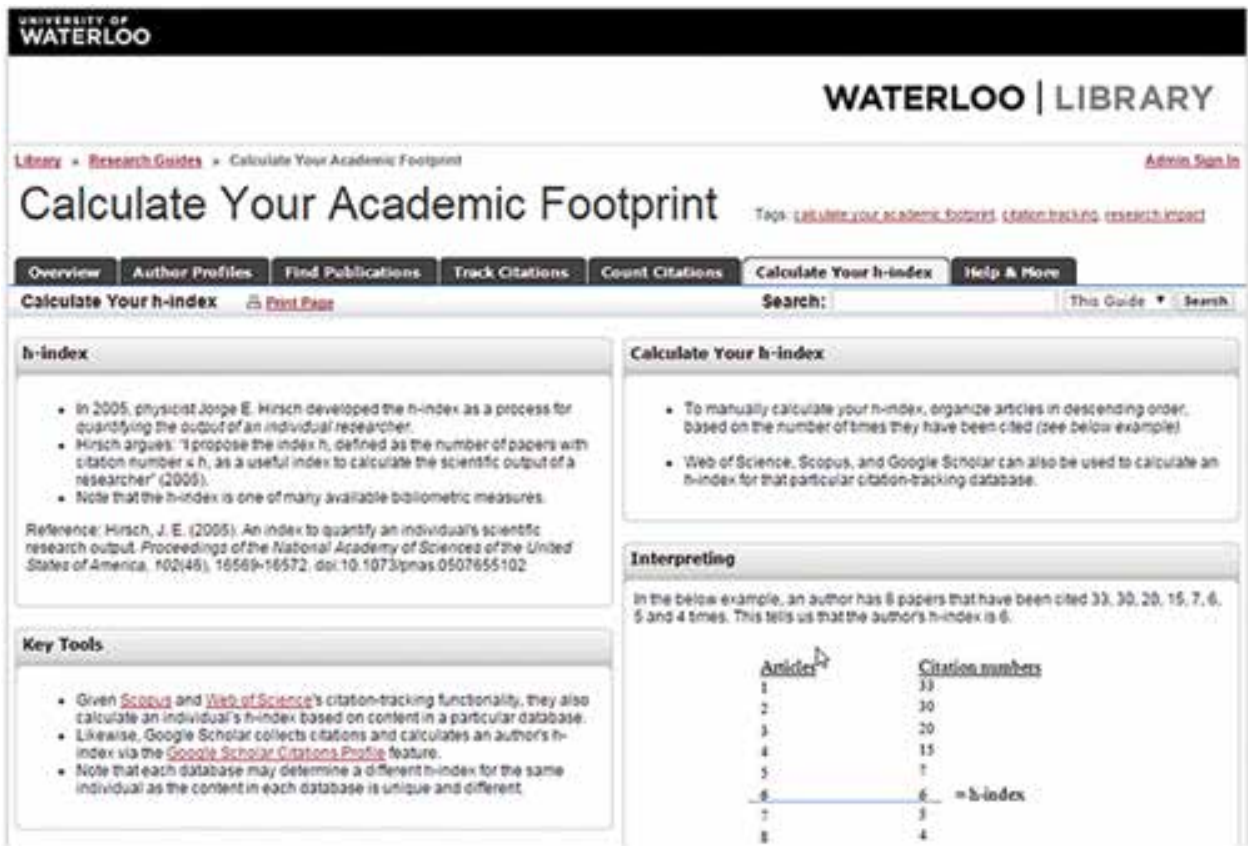

Fig. 4: Site that explain how to calculate an $\mathrm{h}$-index ${ }^{15}$ 
SJR

SCImago

Journal \& Country

Rank
Home

Journal Search

Country Rankings

Country Search

Compare

Map Generator

Help

About Us

Related product

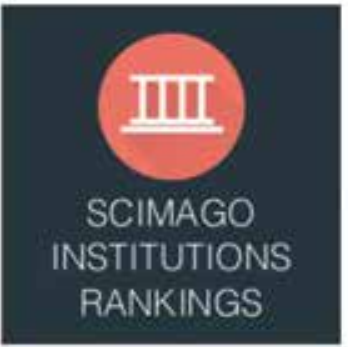

ascimago

SJR is developed by:

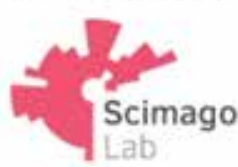

Journal Rankings

Ranking Parameters

Subject Area:

Subject Category:

Region/Country:

Order By:

Display journals with at least:

\section{AII}
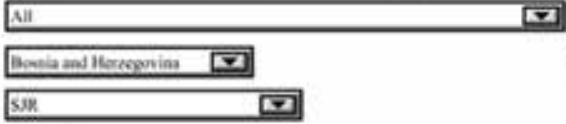

0

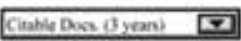

Refresh

Country: Bosnia and Herzegovina.

Year: 2014.

Downtoad data (Excel, xlsx)

\begin{tabular}{|c|c|c|c|c|c|c|c|c|c|c|c|c|}
\hline & Title & Type & S.JR & $\begin{array}{c}\mathbf{H} \\
\text { index }\end{array}$ & $\begin{array}{l}\text { Total } \\
\text { Docs. } \\
(2014)\end{array}$ & $\begin{array}{l}\text { Total } \\
\text { Docs. } \\
\text { (3years) }\end{array}$ & $\begin{array}{l}\text { Total } \\
\text { Refs. }\end{array}$ & $\begin{array}{l}\text { Total } \\
\text { Cites } \\
\text { (3years) }\end{array}$ & $\begin{array}{l}\text { Citable } \\
\text { Docs. } \\
\text { (3years) }\end{array}$ & $\begin{array}{l}\text { Cites I } \\
\text { Doc. } \\
\text { (2years) }\end{array}$ & $\begin{array}{c}\text { Ref. } \\
\text { Doc. }\end{array}$ & Country \\
\hline 1 & $\begin{array}{l}\text { Bosnian Journal of Basic Medical } \\
\text { Sciences }\end{array}$ & j & 0,208 & 11 & 43 & 152 & 844 & 88 & 138 & 0,63 & 19,63 & $\mathbf{M}$ \\
\hline 2 & Medicinski Arthiv & j & 0,168 & 12 & 58 & 336 & 0 & 149 & 328 & 0,45 & 0,00 & $\mathbf{N}$ \\
\hline 3 & Acta Informatica Medica & j & 0,166 & 6 & 84 & 125 & 1.814 & 81 & 115 & 0,70 & 21,60 & $\mathbf{N}$ \\
\hline 4 & Sport Science & j. & 0,157 & 4 & 32 & 108 & 664 & 13 & 108 & 0,10 & 20,75 & $\mathbf{M}$ \\
\hline 5 & Electronies & j & 0,154 & 2 & 13 & 23 & 285 & 6 & 22 & 0.27 & 21,92 & $\mathbf{M I}$ \\
\hline 6 & Acta medica academica & j & 0,137 & 3 & 16 & 56 & 0 & 22 & 50 & 0,44 & 0,00 & $\mathbf{E l}$ \\
\hline 7 & $\begin{array}{l}\text { Intemational Journal of Collaborative } \\
\text { Research on internat Medicine and } \\
\text { Public Health }\end{array}$ & j & 0,136 & 6 & 0 & 198 & 0 & so & 197 & 0,21 & 0,00 & $\mathbf{M}$ \\
\hline 8 & $\begin{array}{l}\text { South East European Journal of } \\
\text { Economics and Business }\end{array}$ & j & 0,126 & 3 & 5 & 46 & 250 & 9 & 46 & 0,23 & 50,00 & W \\
\hline 9 & Veterinaria & j & 0,120 & 2 & 24 & 71 & 550 & 7 & 57 & 0,12 & 22,92 & $\mathbf{M}$ \\
\hline & $\begin{array}{l}\text { Technics Technologies Education } \\
\text { Management }\end{array}$ & j & 0,111 & 6 & 0 & 393 & 0 & 34 & 393 & 0,08 & 0,00 & $\mathbf{a}$ \\
\hline $11+$ & HealthMED & j & 0.110 & 6 & 0 & 903 & 0 & 88 & 902 & 0,11 & 0,00 & $\mathbf{M}$ \\
\hline 12 & Acta Medica Saliniana & j & 0,101 & 2 & 0 & 44 & 0 & 0 & 43 & 0,00 & 0,00 & $\mathbf{M}$ \\
\hline
\end{tabular}

\section{Scopus}

How to cite this website?

Scimaģo Lab, Copyright 2007-2015, Data Source: Scopus?

Fig. 5: H-index of indexed journals in Bosnia and Herzegovina in $2014^{12}$

Publishing in well-known and established journals is the second most important factor; the papers from such journals are more frequently cited. ${ }^{18}$ Working together with recognized members of the scientific community is a quick way to gain more recognition.

Attending the conferences and research meetings may help you to promote your work and search for new collaboration opportunities. Running a blog can also be the way to promote your work. ${ }^{18}$
Another important factor is availability of papers for search and download. The paper should be searchable, that means that paper can be found using the search machine, such as Google Scholars, PubMed, ResearchGate, etc. Publish in open access. Unfortunately the authors of the mentioned paper did not even try to determine, what the influence is of open access on $\mathrm{h}$-index. Oppenness can trigger more citations. ${ }^{18}$ Two kinds of bibliographic tools are used to make scientific publications available 


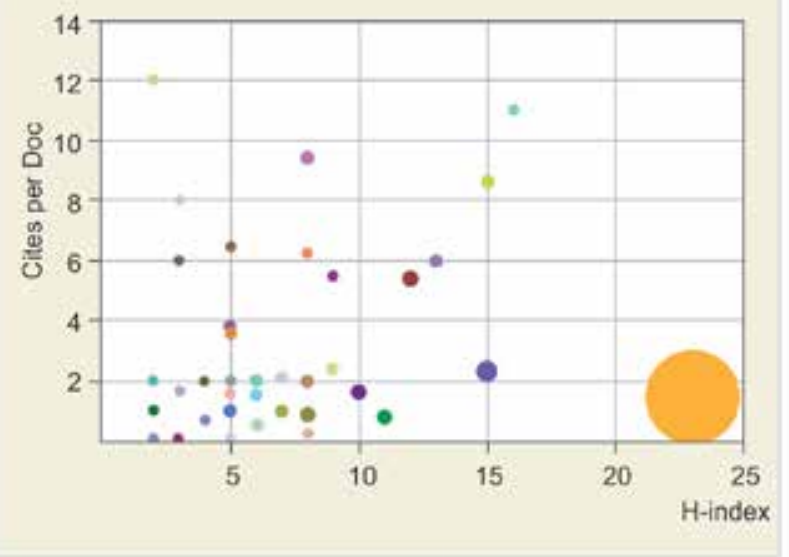

Medicine (miscellaneous
Pharmacology (medical)
Pediatrics, perinatology and child health
$\square$ Pathology and forensic medicine
$\square$ Orthopedics and sports medicine
Radiology, nuclear medicine and imaging
Immunology and allergy
Microbiology (medical)
Complementary and alternative medicine
Epidemiology
Neurology (clinical)
Oncology
Physiology (medical)
Anesthesiology and pain medicine
Geriatrics and gerontology
Pulmonary and respiratory medicine
Cardiology and cardiovascular medicine
Dermatology
Rehabilitation
Rheumatology

Psychiatry and mental health
Surgery
Otorhinolaryngology
Nephrology
Public health, environmental and occupational healtt
$\square$ Gastroenterology
Infectious diseases
Biochemistry (medical)
Endocrinology, diabetes and metabolism
Histology
$\square$ Obstetrics and gynecology
Internal medicine
Transplantation
Emergency medicine
Health informatics
Anatomy
C Critical care and intensive care medicine
Hepatology
Reproductive medicine
Urology

Fig. 6: Cites/Doc. (2 years) parameter vs h-index for medicine fields in period 2012 to 2013 in Bosnia and Herzegovina ${ }^{20}$

online. First kind makes publications available publicly. Another kind requires access fee.

A lot of online scientific journals allow only access to abstract while the full text access requires payment or subscription and registration. If you publish your work in one of such journal it is important to upload copy of your work to one of the online databases, such as ResearchGate. ResearchGate was founded in $2008^{21}$ by a virologist and computer scientist Ijad Madisch. ResearchGate uses a crawler to find PDF versions of articles on the homepages of authors and publishers. ResearchGate uses a crawler to find PDF versions of articles on the homepages of authors and publishers. These are then presented as if they had been uploaded to the website by the author. Free registration is required to access to ResearchGate. ${ }^{21}$

Cyril Labbé has catalogued computer-generated papers that made it into more than 30 published conference proceedings between 2008 and 2013. Sixteen appeared in publications by Springer, which is head quartered in Heidelberg, Germany, and more than 100 were published by the Institute of Electrical and Electronic Engineers (IEEE), based in New York. ${ }^{22}$ Both publishers, which were privately informed by Labbé, say that they are now removing the papers.

The above mentioned papers are generated by SCIgen. That is a program that generates random computer Science research papers, including graphs, figures and citations. It uses a handwritten context-free grammar to form all elements of the papers. ${ }^{23,24}$ The purpose of this program is to prove that a paper will be published by some publisher without reviewing its contents. In 2015 in B\&H about 25 journals are issued in the field of biomedical and life sciences in general -h-index of medical archives for 2014 is 12 (according to scimagojr.com) and is the highest among the journals in B\&H (Figs 5 and 6).

\section{CONCLUSION}

There are a lot of methods to improve your h-score. It takes a lot of work and to promote papers and journals, but it is all part of developing as a researcher, working together with your community and improving communication methods. Some of these methods might be unethical and unpropriate. Evaluation of scholars work would be most reliably done after reviewing of all his papers and citations. That is the best way to see if the h-score is a true representation of the researcher's accomplishments. 


\section{REFERENCES}

1. Available at: http://sciencetechblog.com/2010/05/05/journalimpact-factors-sjr-vs-isi-web-of-knowledge/Cited 2015. Accessed on June 20, 2015.

2. 'Google Scholar Metrics for Publications-Google Scholar Blog'.googlescholar.blogspot.com.br.

3. Jones T, Huggett S, Kamalski J. 'Finding a Way Through the Scientific Literature: Indexes and Measures'. World Neurosurg 76:36.

4. Hirsch, JE. (15 November 2005). 'An index to quantify an individual's scientific research output'. PNAS 102(46): 16569-16572.

5. .arXiv:physics/0508025. Bibcode:2005PNAS..10216569H. doi:10.1073/pnas.0507655102. PMC 1283832. PMID 16275915.

6. Jump up^^ McDonald, Kim (8 November 2005). 'Physicist Proposes New Way to Rank Scientific Output'. PhysOrg. Retrieved 13 May 2010.

7. Garfield E. 'The history and meaning of the journal impact factor.' JAMA 295.1 (2006):90-93.

8. Ostrowska, Aneta. 'Open Access Journals Quality-How to Measure It?.' INFORUM. Vol. 2009. 2009.

9. Available at: http://sciencetechblog.com/2010/05/05/journalimpact-factors-sjr-vs-isi-web-of-knowledge/May 02, 2014).

10. Available at: https://wiki.oulu.fi/display/tor/1.3.1.7.10+ SCImago + Journal + and + Country + Rank (May 02, 2014).

11. Editorial (2009). 'Credit where credit is due'. Nature. 462: 825. doi:10.1038/462825a.
12. Available at: https://wiki.oulu.fi/display/tor/1.3.1.7.10+SCIm ago+Journal+and+Country+Rank (May 02, 2014).

13. Marnett, Alan. 'H-index: What It is and How to Find Yours.' 2010.

14. Egghe L. Dynamic h-index: The Hirsch index in function of time. J Am Soc Inf Sci Technol 2007;58(3):452-454.

15. Available at: http://subjectguides.uwaterloo.ca/content. php?pid=84805\&sid=1885850.

16. Availableat:https://scholar.google.com/intl/en/scholar/about.html

17. Available at: http://transformativelearning.nl/2012/04/26/ publish-or-perish-improving-your-h-factor-made-easythrough-hbay/

18. Available at: http://openscience.com/should-you-care-aboutyour-h-index-and-if-so-how-to-improve-it/

19. Masic I. Scientometric analysis: a technical need for medical science researchers either as authors or as peer reviewers. J Res Pharm Pract 2016;5:1-6.

20. Masic I, Begic E, Zunic L. Scientometric Analysis of Scientific Validity of Medical Archives Regading Other Medical Journals in Bosnia and Herzegovina. Med Arch 2016;70:18-26.

21. Available at: https://en.wikipedia.org/wiki/ResearchGate.

22. Lin, Thomas (16 January 2012). "Cracking open the scientific process". The New York Times. Retrieved 26 June 2014).

23. Available at: https://pdos.csail.mit.edu/archive/scigen/).

24. Labbé C, Labbé D. Duplicate and fake publications in the scientific literature: how many SCIgen papers in computer science?. Scientometrics. 2013;94(1):379-396. 